\title{
Long-term health-related quality of life and survival after cardiac surgery: A prospective study
}

Kari Hanne Gjeilo, RN, PhD, ${ }^{\text {a,b,c,d }}$ Roar Stenseth, MD, PhD, ${ }^{\text {d,e }}$ Alexander Wahba, MD, PhD, ${ }^{\mathrm{a}, \mathrm{d}}$

Stian Lydersen, $\mathrm{PhD},{ }^{\mathrm{f}}$ and Pål Klepstad, $\mathrm{MD}, \mathrm{PhD}^{\mathrm{d}, \mathrm{g}}$

\section{ABSTRACT}

Objectives: Health-related quality of life (HRQOL) is an important end point after cardiac surgery, particularly in patients of older age. However, prospective long-term studies describing the trajectory of HRQOL after cardiac surgery are still scarce. Therefore, the aim was to assess survival, functional status, and trajectory of HRQOL 10 years after cardiac surgery.

Methods: In a prospective population-based study, 534 patients $(23 \%$ aged 75 years or older, $67 \%$ male) were consecutively included before surgery. Functional status was measured according to self-assigned New York Heart Association (NYHA) classification. HRQOL was measured using the ShortForm Health Survey (SF-36). Questionnaires were given to the patients at baseline and sent by post at 6 and 12 months, and 5 and 10 years after surgery.

Results: Three hundred fifty-two patients were eligible after 10 years, 274 responded $(77.8 \%)$. Total survival at 10 years was $67.8 \%$. Patients aged 75 years or older at surgery had lower survival rates than younger patients $(44.6 \%$ vs $74.6 \%, P<.001)$. Seven of 8 SF-36 subscales were improved at 10 years compared with baseline. Older patients improved less than younger patients and linear mixed models showed that older patients had significantly worse trajectories on 3 of 8 SF-36 subscales. NYHA classification improved from baseline to 10 years also among older patients, with $59 \%$ in NYHA class III/IV at baseline compared with $30.3 \%$ after 10 years $(P<.013)$.

Conclusions: HRQOL and function improved from before to 10 years after cardiac surgery, also for older patients. These long-term results are of major importance when discussing the use of health care resources and patient-centered clinical decision-making. (J Thorac Cardiovasc Surg 2018;156:2183-90)

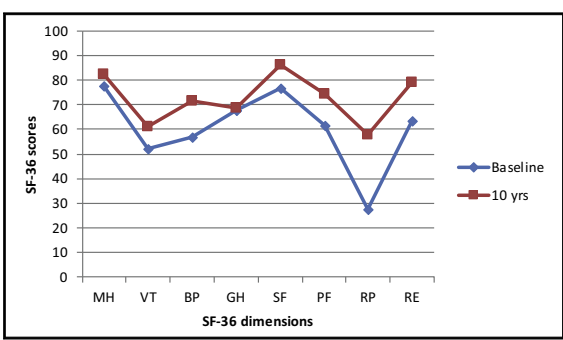

SF-36 scores before and 10 years after surgery on each SF-36 dimension.

\section{Central Message}

Long-term benefits in terms of function and health-related quality of life are sustained up to 10 years after cardiac surgery, also for elderly patients.

\section{Perspective}

Patient-reported outcomes are important after cardiac surgery. Health-related quality of life and function improved from before to 10 years after cardiac surgery, confirming a long-term benefit. These results are important in discussions of the use of health care resources and should be implemented in patient-centered clinical decision-making, especially in older patients.

See Editorial Commentaries pages 2191 and 2192.
Patient-reported outcome measures (PROMs), particularly health-related quality of life (HRQOL) domains of physical, emotional, and social functioning (SF), are

\footnotetext{
From the Departments of a Cardiothoracic Surgery, ${ }^{\mathrm{b}}$ Cardiology, ${ }^{\mathrm{e}}$ Cardiothoracic Anaesthesiology, and ${ }^{\mathrm{g}}$ Intensive Care Medicine, and ${ }^{\mathrm{c}}$ National Competence Centre for Complex Symptom Disorders, St Olavs Hospital, Trondheim University Hospital, Trondheim, Norway; ${ }^{\mathrm{d}}$ Department of Circulation and Medical Imaging, and ${ }^{\mathrm{f}}$ Department of Mental Health, Regional Centre for Child and Youth Mental Health and Child Welfare-Central Norway, Faculty of Medicine and Health Sciences, NTNU, Norwegian University of Science and Technology, Trondheim, Norway.

Received for publication Oct 27, 2017; revisions received May 4, 2018; accepted for publication May 12, 2018; available ahead of print July 4, 2018.

Address for reprints: Kari Hanne Gjeilo, RN, PhD, Department of Cardiothoracic Surgery, St Olavs Hospital, Postboks 3250 Sluppen, Trondheim N- 7006, Norway (E-mail: kari.hanne.gjeilo@stolav.no).

$0022-5223 / \$ 36.00$

Copyright (c) 2018 by The American Association for Thoracic Surgery https://doi.org/10.1016/j.jtcvs.2018.05.087
}

increasingly recognized as key measures of surgical success after cardiac surgery, especially in the elderly cardiac surgery population. ${ }^{1-4}$ This is also reflected in guidelines and statements in which PROMs are acknowledged as main outcomes of cardiovascular health along with mortality and morbidity. ${ }^{2,5}$ Therefore, to understand the effect of cardiac surgery on PROMs such as HRQOL is important. This information can guide patient-centered clinical decision-making and counseling patients so that

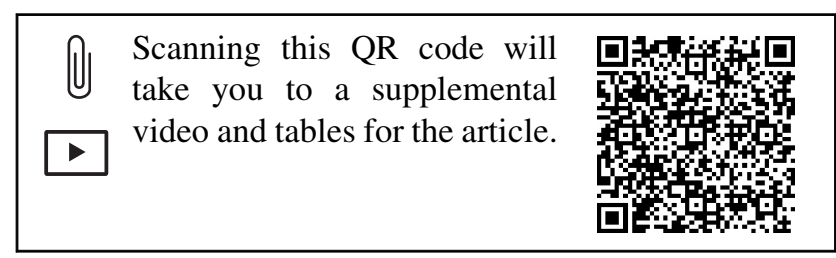




Abbreviations and Acronyms
$\begin{aligned} \text { CABG } & =\text { coronary artery bypass grafting } \\ \text { CI } & =\text { confidence interval } \\ \text { EuroSCORE } & =\text { European System for Cardiac } \\ & \text { Operative Risk Evaluation } \\ \text { GH } & =\text { general health } \\ \text { HR } & =\text { hazard ratio } \\ \text { HRQOL } & =\text { health-related quality of life } \\ \text { NYHA } & =\text { New York Heart Association } \\ \text { PROM } & =\text { patient-reported outcome measure } \\ \text { RP } & =\text { role physical } \\ \text { SF } & =\text { social functioning } \\ \text { SF-36 } & =\text { Short-Form Health Survey } \\ \text { VT } & =\text { vitality }\end{aligned}$

their expectations are aligned with their likely outcome. ${ }^{3,6}$ Hence, it might be important for appropriate patient selection.

Despite the increased recognition of the importance of PROMs, the quality of the studies on this topic is criticized and quality of life after cardiac surgery has been described as "under-researched research." 1,3,7,8 With improved long-term survival, extended focus on functional status and HRQOL beyond the first few years after surgery is important. Most studies conclude that HRQOL improves after cardiac surgery procedures, also among elderly patients. ${ }^{1,8,9}$ However, controversies still remain concerning how long the benefit lasts, especially among the oldest. Blokzijl and colleagues reported a significant difference between the benefit in younger and elderly patients 1 year after coronary artery bypass grafting $(\mathrm{CABG}),{ }^{10}$ whereas Loponen and colleagues showed that older patients returned to preoperative levels as early as 18 months after $\mathrm{CABG} .{ }^{11} \mathrm{~A}$ systematic review from 2013 concluded that aortic valve replacement results in significant HRQOL benefits across a broad range of health domains also in elderly patients. ${ }^{12}$ Despite the increasing number of studies on this topic, the strength of the evidence varies because of methodological shortcomings such as in retrospective studies and lack of baseline data. Further, there are few longitudinal studies that have evaluated long-term changes in HRQOL, ${ }^{13-15}$ and even fewer with a special emphasis on outcomes in the elderly. Therefore, the aim of the present prospective study was to follow the trajectory of HRQOL and survival from baseline and up to 10 years after cardiac surgery and to compare elderly (aged 75 years or older at the time of surgery) versus younger patients.

\section{METHODS \\ Patients}

All patients who underwent cardiac surgery at the Department of Cardiothoracic Surgery, St Olavs Hospital between September 2004 and September 2005 were consecutively assessed for inclusion in the study. The department is the only cardiac surgery service in the central region of Norway. The perioperative treatment and care followed a fast-track regimen and all patients had sternotomy. Of 631 patients who underwent cardiac surgery, 97 patients were excluded (Figure 1). Thus, 534 patients were included in the study at baseline $(84.6 \%)$. Questionnaires were given to the patients for self-administration after admission for surgery (baseline), and posted 6 and 12 months, 5 and 10 years after surgery. Results of the 5-year follow-up have been reported previously. ${ }^{16}$

The study was approved by the Regional Committee for Medical and Health Research Ethics (project 2012/1559/REK midt). Written informed consent was obtained from each patient at inclusion and again after 5 and 10 years. Nonresponders were sent 1 postal reminder 4 weeks after the initial questionnaire. Those who did not respond were considered nonresponders.

\section{Measures}

Study-specific questionnaires concerning sociodemographic and medical variables were constructed, including self-assigned New York Heart Association (NYHA) classification. ${ }^{17}$ Medical and surgical information was collected from an institutional database. The European System for Cardiac Operative Risk Evaluation (EuroSCORE) was calculated according to the additive method. ${ }^{18}$ Patients were followed-up with respect to survival using computerized linkage to the continuously updated National Population Register, a public register including all

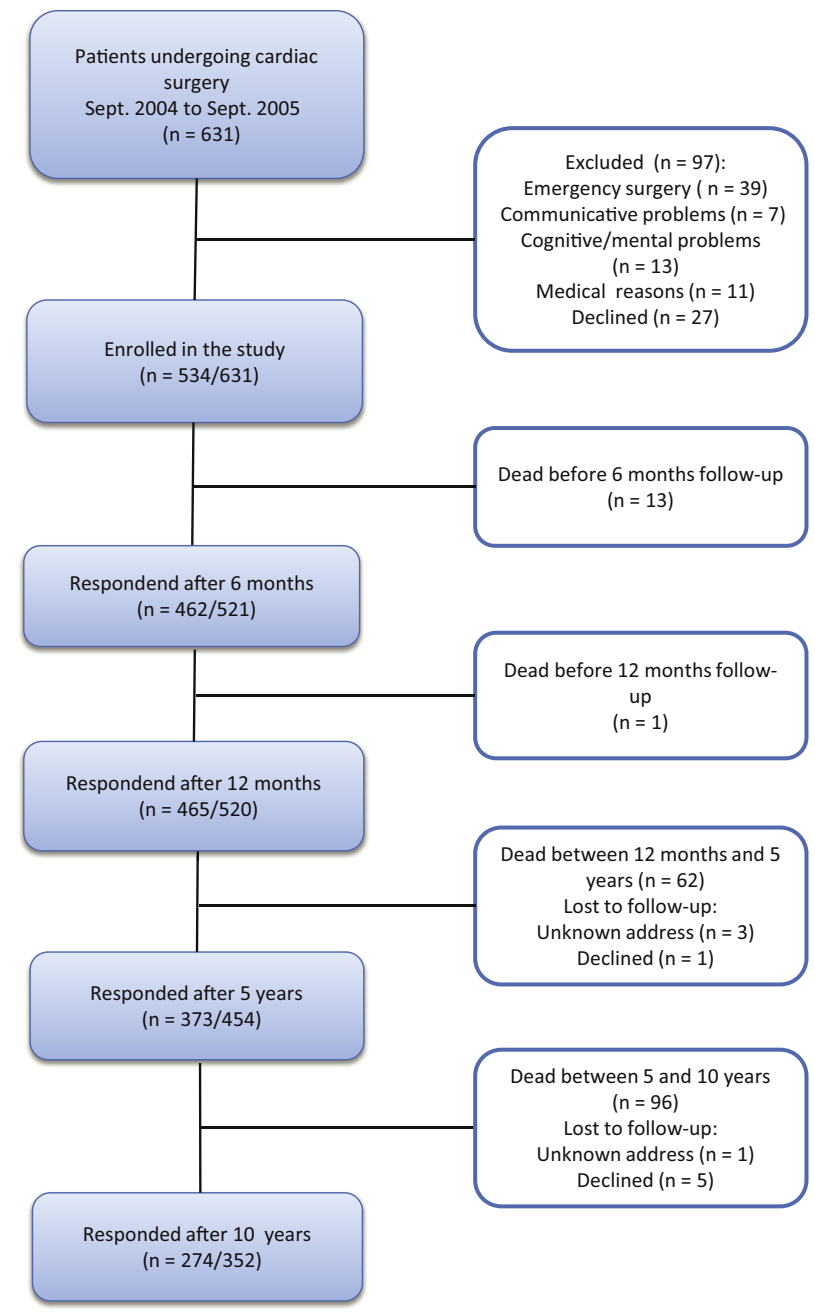

FIGURE 1. Flow of patients through the study. Sept., September. 
registered residents living in Norway. The unique national registration numbers assigned to each Norwegian citizen enabled accurate linkage.

The Short-Form Health Survey (SF-36) was used to assess HRQOL (version 1.2). The SF-36 consists of 36 items used to measure 8 domains of health: general health (GH), physical functioning, bodily pain, mental health, role limitations due to physical problems (RP), role limitations due to emotional problems, vitality (VT), and social functioning (SF). As recommended in the SF-36 health survey manual and interpretation guide by Ware and colleagues the scores in each domain are transformed into 0 to 100 scales; higher scores reflect better health. ${ }^{19}$ SF-36 scores can either be presented as raw scale scores (0-100) or normalized scores $(50 \pm 10)$. In the present report, data are presented as raw scores. SF-36 has undergone extensive validation in several countries, including Norway ${ }^{20}$ and in different patient populations, including cardiac surgery. ${ }^{4,21}$ If at least half of the items in a scale in the SF-36 were answered by a patient at a time point, the mean score on that scale was used, as described in the SF-36 manual. ${ }^{19}$

\section{Statistical Analysis}

Descriptive data are given as mean (SD), median (range) and number $(\%)$ respectively. Baseline patient data were compared using the Mann-Whitney $U$ test or the Student $t$ test for continuous variables. The unconditional z-pooled test (Suissa Shuster exact unconditional test), Fisher exact test, exact linear-by-linear association test, and marginal homogeneity test (score test) were used for comparing 2 independent proportions, 2 independent multinomials, analyzing the association between 2 ordinal variables, and comparing matched ordinal variables, respectively. ${ }^{22}$ We checked normality by inspecting Q-Q plots.

Differences in HRQOL were analyzed using Student $t$ tests on one assessment point whereas paired samples $t$ tests were used to compare data at baseline and 10-year follow-up. Linear mixed models were used to examine the evolution of HRQOL over the 5 time points of measurements. The model was fitted with each SF-36 dimension as the dependent variable, time, age group (younger vs older than 75), interaction between time and age group, and sex as fixed factors, and subjects as random factors.

Survival analyses with "time since surgery" as time variable and "death" as event were performed by mortality curves on the basis of the Kaplan-Meier estimator, log-rank test, and Cox proportional hazards regression. The proportional hazards assumption was checked by visual inspection of $\log$ minus log survival plots. Hazard ratios (HRs) with 95\% confidence intervals (CIs) and $P$ values are reported for the Cox regression models.

The unconditional z-pooled test was carried out using StatXact11 (Cytel, Cambridge, Mass) and Cox regression was carried out in Stata 13 (StataCorp, College Station, Tex). All other analyses were performed using SPSS Statistics for Windows, version 23.0 (IBM Corp, Armonk, NY). Two-sided $P$ values $<.05$ were considered statistically significant.

\section{RESULTS}

Of the original cohort included at baseline, 172 patients had died and 6 patients were lost to the 10-year follow-up. Hence, 352 patients were eligible at 10 years, of whom 274 responded $(77.8 \%)$. The patient flow through the study is outlined in Figure 1. Among the responding patients, $36(13.1 \%)$ were 75 years or older at the time of surgery (Table 1). Responders and nonresponders differed significantly concerning sex and EuroSCORE, with a lower proportion of female participants and lower EuroSCORE among responders.

The mean age when responding was 74.2 (9.75; range, $35-96)$ years, $89(32.5 \%)$ were older than 80 years, and
$6(2.2 \%)$ patients were 90 years or older. The mean follow-up time since surgery was $10.1(0.07)$ years.

\section{Long-Term Survival}

Data on survival were available on all patients; hence no patients were censored before 10 years (Figure 2). All-cause mortality was $32.2 \%$ (172 of 534). Compared with younger patients, older patients (aged 75 years or older) had a 10-year survival of $44.6 \%$ (67 of 121) compared with $74.6 \%$ (105 of 413$)$ for younger patients (log rank test, $P<.001$; Figure 2).

Cox regression analysis showed that men had lower mortality than women (HR, 0.71; 95\% CI, 0.51-0.99; $P=.042)$. However, men were on the average younger than women (66.0 years vs 70.0 years of age at surgery; $P<.001)$. Sex did not have an effect on mortality when adjusting for age (HR, 0.97; 95\% CI, 0.69-1.36; $P=.844)$ whereas age had an effect on mortality adjusted for sex (HR [per 10 years increase in age], 2.23; 95\% CI, $1.83-2.72 ; P<.001)$. Including type of surgery in 4 categories did not substantially change the effect of age and the lack of effect of sex adjusted for age. The overall effect of surgery was not statistically significant $(P=.050,3 d f)$. However, there was a tendency for patients who received $C A B G$ with heart valve surgery to have higher mortality compared with those who had isolated CABG (HR, 1.60; CI, 1.09-2.34; $P=.017$; see Table E1).

\section{Function and HRQOL}

There was a statistically significant improvement in self-assigned NYHA classification from baseline to 10 years in the total study population (marginal homogeneity test, $P<.001$ ), also when subgroup analyses were performed according to age at surgery younger than 75 years, $P<.001$ and 75 years or older, $P=.013$. For example, among older patients, $54.6 \%$ reported to be in NYHA class III/IV at baseline compared with $30.3 \%$ after 10 years. Details are shown in Tables E2 to E4.

Preoperative SF-36 scores were consistently lower among nonresponders than responders, with $\mathrm{GH}$, mental health, VT, and SF preoperatively being statistically lower among nonresponders than responders (Table 1). In general, HRQOL improved from before to 10 years after surgery (Table 2). The mean changes ranged from 1.1 points on GH to 30.5 points on RP. On 7 of 8 subscales the improvement reached statistical significance. Linear mixed models revealed that patients younger than 75 years versus patients aged 75 years or older at the time of surgery had significantly different trajectories of HRQOL on 3 of 8 subscales: physical functioning, SF, and RP. The trajectory also differed on VT, not reaching statistical significance. Figure 3 illustrates the linear mixed models of the trajectories on each of the 8 SF-36 dimensions separately (see also Table E5). 
TABLE 1. Baseline demographic and clinical characteristics and preoperative health-related quality of life among patients being dead, nonresponders, or responders at 10-year follow-up

\begin{tabular}{|c|c|c|c|c|}
\hline Characteristic & $\operatorname{Dead}(n=172)$ & Nonresponders $(\mathbf{n}=\mathbf{8 8})$ & Responders $(n=274)$ & $P$ value* \\
\hline Mean age at surgery (SD), y & $72.5(7.7)$ & $64.9(13.1)$ & $64.1(9.9)$ & $.591 \dagger$ \\
\hline 75 Years or older, $\mathrm{n}(\%)$ & $67(39.0)$ & $18(20.5)$ & $36(13.1)$ & $.096 \ddagger$ \\
\hline Female sex, n $(\%)$ & $47(27.3)$ & $28(31.8)$ & $46(16.8)$ & $.002 \ddagger$ \\
\hline Smoking status, $\mathrm{n}(\%) \S$ & & & & $1.000 \|$ \\
\hline Current & $29(16.9)$ & $15(17.2)$ & $30(10.9)$ & \\
\hline Former & $104(60.5)$ & $43(49.4)$ & $169(61.7)$ & \\
\hline Never & $39(22.7)$ & $29(33.3)$ & $75(27.4)$ & \\
\hline Previous cardiac surgery, n (\%) & $12(7.0)$ & $6(6.8)$ & $21(7.7)$ & $.802 \ddagger$ \\
\hline Diabetes mellitus, n (\%) & $37(21.5)$ & $13(14.8)$ & $21(7.7)$ & $.047 \ddagger$ \\
\hline Mean BMI (SD) & $26.7(4.1)$ & $26.1(3.9)$ & $27.2(3.7)$ & $.124 \pi$ \\
\hline Self-assigned NYHA class, $\mathrm{n}(\%) \S$ & & & & $.422 \|$ \\
\hline I & $15(9.3)$ & $10(11.4)$ & $55(20.2)$ & \\
\hline II & $59(36.6)$ & $38(44.7)$ & $103(37.9)$ & \\
\hline III & 67 (41.6) & $32(37.6)$ & $94(34.6)$ & \\
\hline IV & $20(12.4)$ & $5(5.9)$ & $20(7.4)$ & \\
\hline Median EuroSCORE (range) & $5.5(0-13.0)$ & $4.0(0-11.0)$ & $3.0(0-13.0)$ & $.012 \dagger$ \\
\hline Median XC time (range), minutes & $45.5(13.0-273.0)$ & $43.5(12.0-183.0)$ & $40.0(5.0-180.0)$ & $.385 \dagger$ \\
\hline Median CPB time (range), minutes & $76(26.0-441.0)$ & $68.5(27.0-263.0)$ & $64.0(16.0-206)$ & $.398 \dagger$ \\
\hline Cardiac surgery, n (\%) & & & & $.138 \#$ \\
\hline Isolated CABG & $103(59.9)$ & $56(63.6)$ & $206(75.2)$ & \\
\hline Isolated HVS & $10(5.8)$ & $8(9.1)$ & $18(6.6)$ & \\
\hline CABG with HVS & $40(23.3)$ & $13(14.8)$ & $22(8.0)$ & \\
\hline Miscellaneous & $19(11.0)$ & $11(12.5)$ & $28(10.2)$ & \\
\hline \multicolumn{5}{|l|}{ Mean SF-36 scores (SD) } \\
\hline General health & $60.6(20.3)$ & $60.9(19.9)$ & $68.1(19.1)$ & $.005 \pi$ \\
\hline Mental health & $73.0(17.4)$ & $73.0(18.3)$ & $78.1(17.4)$ & $.026 \pi$ \\
\hline Vitality & $45.9(21.1)$ & $45.4(23.9)$ & $51.8(23.3)$ & $.032 \pi$ \\
\hline Bodily pain & $54.0(27.6)$ & $53.7(27.8)$ & $57.1(26.5)$ & $.330 \rrbracket$ \\
\hline Social functioning & $65.5(26.3)$ & $69.0(27.2)$ & $76.9(22.4)$ & $.018 \pi$ \\
\hline Physical functioning & $48.5(25.1)$ & $55.1(28.2)$ & $62.0(26.5)$ & .0519 \\
\hline Role physical & $12.0(27.4)$ & $18.9(34.7)$ & $27.5(38.1)$ & .0579 \\
\hline Role emotional & $47.6(44.5)$ & $54.2(44.2)$ & $62.8(41.7)$ & $.125 \pi$ \\
\hline
\end{tabular}

Descriptive data are given as frequencies (\%), mean (SD) and median (range). SD, Standard deviation; $B M I$, body mass index; NYHA, New York Heart Association; EuroSCORE, European System for Cardiac Operative Risk Evaluation; $X C$, cross clamp; $C P B$, cardiopulmonary bypass; $C A B G$, coronary artery bypass grafting; $H V S$, heart valve surgery; $S F$-36, Short-Form Health Survey. *Statistical comparison of responders and nonresponders. $\dagger$ Mann-Whitney $U$ test. $\ddagger$ Unconditional z-pooled test. §n varies between the variables because of missing values. $\|$ Linear by linear association exact test. $\mid t$ test, equal variances not assumed. \#Fisher exact test.

\section{DISCUSSION}

This prospective cohort study addressed long-term survival, function, and HRQOL after cardiac surgery. The main finding was that HRQOL generally was improved from before to 10 years after cardiac surgery. However, there was a decline on some SF-36 subscales from 12 months to 5 and 10 years, especially for older patients.

\section{Survival}

A 10 -year survival of $68 \%$ is similar to that reported in other studies after cardiac surgery. Herlitz and colleagues ${ }^{13}$ reported $68 \%$ survival and Dunning and colleagues ${ }^{15}$ reported $66 \%$ survival 10 years after $\mathrm{CABG}$, whereas a
Finnish study reported a 10 -year survival of $79 \% .{ }^{14}$ These studies included only isolated CABG procedures and patients at a younger age. In addition, the studies were older reports. This hampers the comparison with our mixed cardiac surgery population, including procedures with higher mortality risk and illustrates the challenges in comparing studies of different cardiac surgery populations. In a retrospective study of long-term survival after isolated aortic valve replacement all-cause mortality was reported to be $23.1 \%$ at 5 years, $48.3 \%$ at 10 years, and $67.9 \%$ at 15 years postoperatively. ${ }^{23}$

Men had lower mortality rates than women, but sex was not a predictor of survival after 10 years when adjusting for age and type of surgery. Studies of sex differences in 


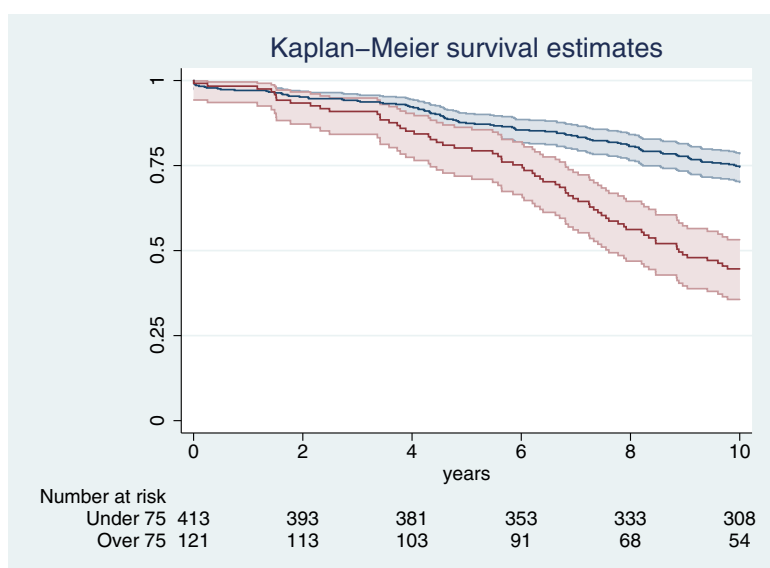

FIGURE 2. Kaplan-Meier survival estimates with $95 \%$ confidence intervals. Red line for patients aged 75 years or older and blue line for patients younger than 75 years at the time of surgery. Log rank test, $P=.001$.

survival after cardiac surgery seem to be inconclusive and controversial. For example, a study by Attia and colleagues $^{24}$ reported a lower time-related survival after CABG for women compared with men, even after risk adjustment. A meta-analysis by Alam and colleagues concluded that women had higher short-term, mid-term, and long-term mortality rates compared with men. ${ }^{25}$ In contrast, Nicolini and colleagues reported similar cumulative rates of all cause-mortality for men and women in a propensity-matched cohort 5 years after $\mathrm{CABG}$, and concluded that female sex was not an independent risk factor for mortality. ${ }^{26}$ Different conclusions concerning sex and mortality might be related to the heterogeneity in studies, methodological challenges, and the smaller proportion of women who undergo cardiac surgery. Further, women tend to be older and have greater comorbidity than men-hence having a less favorable risk profile. ${ }^{25}$

Long-term survival was, as expected, better among younger patients (younger than 75 years at the time of surgery), but the survival curve showed similar survival between younger and older patients during the first years after surgery. We have previously published analyses of relative survival after 5 years, ${ }^{16}$ and in line with other studies we reported that younger patients had lower relative survival rates than the general population and older patients had similar or even better relative survival. ${ }^{27} \mathrm{We}$ did not calculate relative survival after 10 years, however another publication from our center concluded that cardiac surgery patients showed survival comparable with that expected in the general Norwegian population. ${ }^{28}$ Taken together, the studies underline the survival benefit of cardiac surgery in appropriately selected patients.

\section{Function and HRQOL}

In our data, the typical trajectory for most SF-36 scales was a distinct increase between baseline and 6 months, stabile function between 6 and 12 months, a decrease from 12 months to 5 years, and a further minor deterioration from 5 to 10 years. Patient-reported NYHA classification followed the same pattern, a finding in line with a systematic review concluding that improvement in NYHA classification persisted long-term. ${ }^{12}$ Interestingly, the benefit of cardiac surgery on function and HRQOL was sustained up to 10 years for the cohort as a whole. However, over the years there was a decline, especially among older patients. This was most pronounced in physical functioning and might be an expected natural functional decline because of aging. ${ }^{29}$ Previous studies support the influence of age itself as most important, because HRQOL of elderly patients after cardiac surgery was similar to that of an age-matched general population, ${ }^{1}$ a finding also observed in our study. ${ }^{16,29}$

Despite an ongoing deterioration 10 years after the surgery, overall there was a significant improvement in HRQOL and function compared with preoperative values, also among older patients. Previous studies considering changes in HRQOL after cardiac surgery have brought out conflicting views and conclusions. ${ }^{30}$ It has especially been debated if and how long older patients benefit after

TABLE 2. Mean (SD) change in SF-36 scores for patients at baseline and 10 years after cardiac surgery

\begin{tabular}{|c|c|c|c|c|}
\hline SF-36 dimension & Baseline & $10 y$ & Mean change & $P$ value* \\
\hline General health & $67.4(19.3)$ & $68.9(22.0)$ & $1.1(24.0)$ & .476 \\
\hline Physical functioning & $61.7(26.3)$ & $74.2(25.7)$ & $12.5(30.4)$ & $<.001$ \\
\hline Social functioning & $76.6(22.6)$ & $86.0(21.5)$ & $9.4(26.1)$ & $<.001$ \\
\hline Role physical & $27.4(38.0)$ & $57.9(44.2)$ & $30.5(51.8)$ & $<.001$ \\
\hline Role emotional & $63.3(41.7)$ & $78.9(34.9)$ & $15.6(47.4)$ & $<.001$ \\
\hline Mental health & $77.7(17.5)$ & $82.4(15.4)$ & $4.7(18.8)$ & $<.001$ \\
\hline Vitality & $52.0(22.58)$ & $61.2(21.5)$ & $9.2(23.8)$ & $<.001$ \\
\hline Bodily pain & $56.8(26.4)$ & $71.7(27.6)$ & $14.9(33.2)$ & $<.001$ \\
\hline
\end{tabular}

Analyses were performed only on patients with complete scale scores at baseline and at follow-up at 10 years, with an $\mathrm{n}$ ranging from 236 to 261 . $S F$-36, Short-Form Health Survey. *Paired samples $t$ test. 
Bodily Pain (BP)

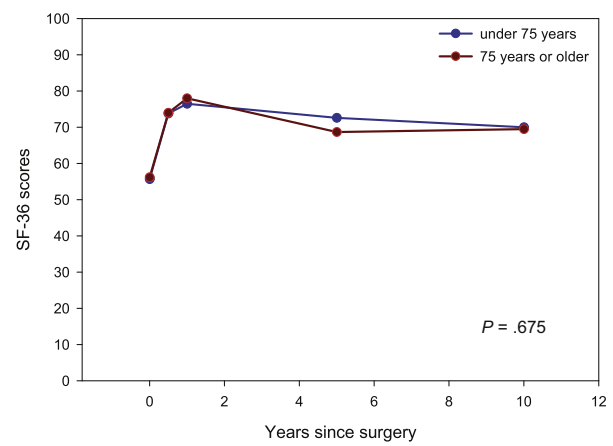

Mental Health (MH)

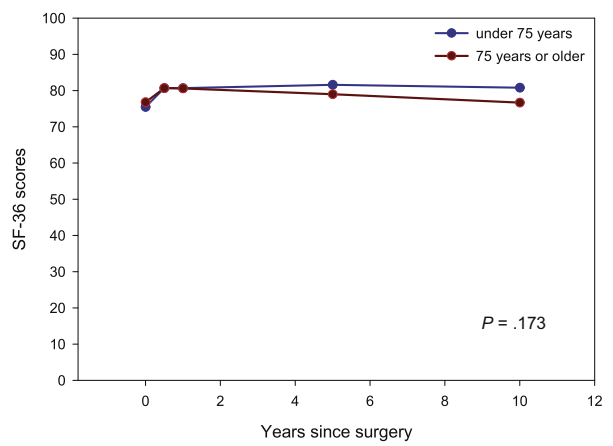

Role Emotional (RE)

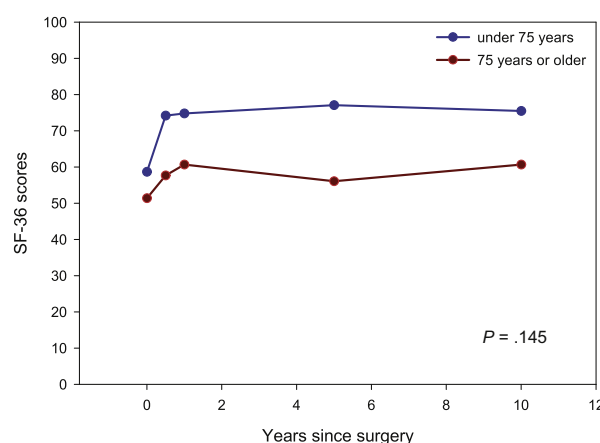

Social Functioning (SF)

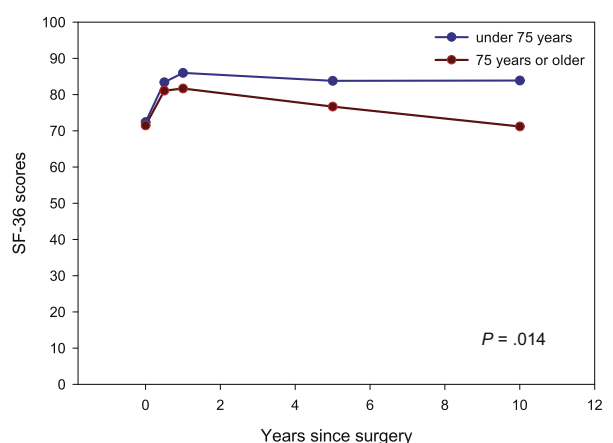

General Health (GH)

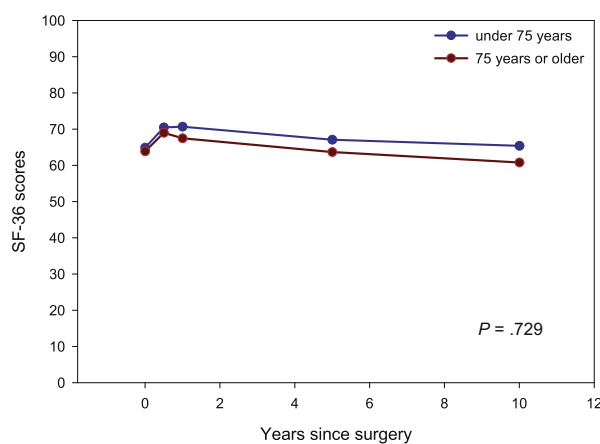

Physical Functioning (PF)

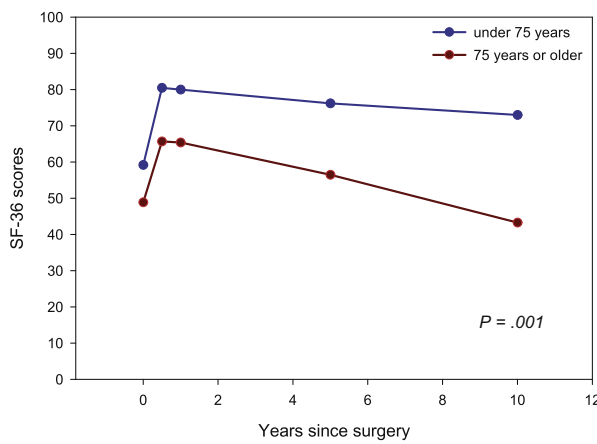

Role Physical (RP)

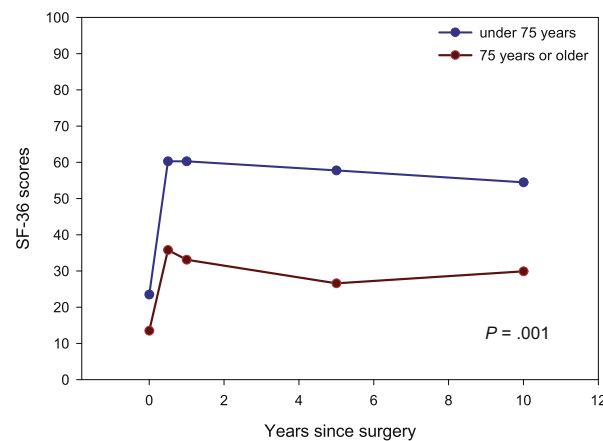

Vitality (VT)

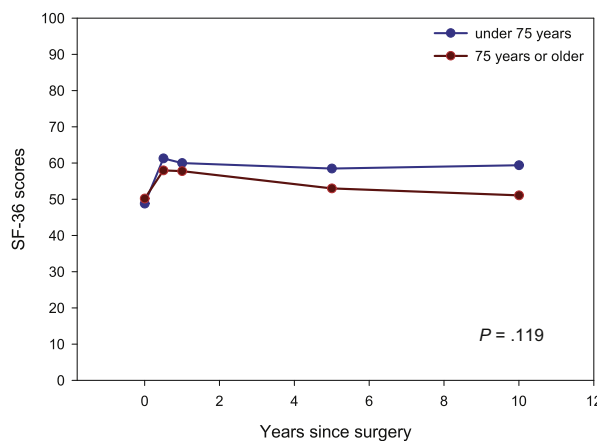

FIGURE 3. Trajectory of the Short-Form Health Survey (SF-36) scores from baseline to 10 years after surgery. Linear mixed models used to compare patients younger than 75 years and patients 75 years of age or older at the time of surgery on each SF-36 subscale separately. Time points are indicated on the $x$-axis and SF-36 scores on the $y$-axis. Measures of variability and number of patients at each time point are shown in Table E5. 


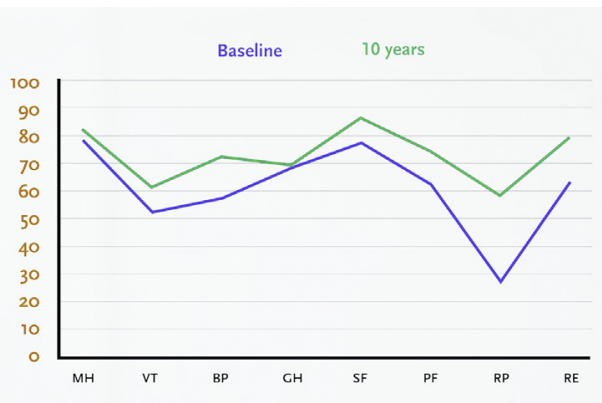

VIDEO 1. The authors explaining the importance and relevance of the study. Video available at: https://www.jtcvs.org/article/S0022-5223(18) 31523-X/fulltext.

cardiac surgery. ${ }^{3}$ Our study confirmed a sustained benefit in HRQOL and function over time. Good results in the present study, also for older patients, might reflect patient selection for cardiac surgery at our center. Methodologically this might be viewed as a selection bias, and results might be different at other centers. Thus, an unresolved question is to find the optimal threshold in preoperative health status to be accepted for cardiac surgery and to expect a good long-term outcome. Certainly, to refer the "right" patients to surgery is an important clinical issue.

As recently highlighted in an editorial commentary by Hammon, ${ }^{31}$ it is imperative to have baseline values and to follow patients at regular intervals over time to ensure reliable evidence on HRQOL outcomes. The commentary was a response to a study by Luckraz and colleagues, who concluded that HRQOL in octogenarians is preserved irrespective of the time interval from surgery. ${ }^{32}$ However, HRQOL was measured retrospectively, at widely different time periods from surgery. On the basis of this and other studies it might be argued that lack of evidence from rigorous methodologically sound studies still limits the use of HRQOL assessment in clinical decision-making. ${ }^{1,3}$ To establish the expected long-term consequences after cardiac surgery, for mortality and HRQOL, is important especially for the older patients. The decision regarding treatment strategy in the elderly population is multifactorial. Individualized patient assessment should identify health status, frailty, HRQOL, and cardiac symptoms. An understanding of these factors together, other unique aspects of risk, as well as individual patient goals, can assist in defining prognosis and refine decision-making in this vulnerable population. ${ }^{33,34}$ Further, it is important that patient expectations are brought forward, because HRQOL might be viewed as the gap between reality and expectations. Together with known risk factors the expected patient trajectories presented in this report might be implemented to guide patient expectations and aid the patient's decision-making (Video 1).

\section{Strengths and Limitations}

We recognize some strengths and limitations in this study. First, one strength is that the overall percentage of patients included at baseline and response rate at the follow-up are good compared with other postal surveys. Second, this study screened for inclusion of all patients having cardiac surgery within a defined time period and a defined health care region, thereby representing a true consecutive population-based sample. Third, this study fulfilled all of the 10 criteria assessing the methodological quality of HRQOL studies of patients undergoing CABG as proposed by Baig and colleagues. ${ }^{3}$ These criteria include using standardized validated HRQOL questionnaires, participation, and response rates over $75 \%$ and measuring different domains of HRQOL. Further, in contrast to most previous studies, our study did include preoperative quality of life assessments and did clearly define the length of follow-up with a minimum variation at each assessment point.

A limitation shared by all longitudinal surveys is the healthy responder effect, which might also represent a natural selection. In the present study, the latter might be especially relevant from 5 to 10 years because only $45 \%$ of the patients older than 75 were alive after 10 years. These complicated issues must be kept in mind when implementing evidence from longitudinal studies into clinical decision-making. In this cohort (Table 1) some of the baseline characteristics (for example, sex) differed between the nonresponders, responders, and patients passed away before 10 years. Hence, data were not missing completely at random. ${ }^{35}$ Some patients missed observations at 1 or more of the time points during the study period. The use of a mixed model addressed that all patients observed after 10 years could be included in the analysis. Second, this study reported overall survival, not cardiac-specific mortality because it was not possible to determine the cause of death for many patients. In long-term follow-up studies of survival after an initial event (eg, cardiac surgery), mortality from causes other than the one under study obscures the results, especially in elderly patients. ${ }^{27}$ However, for the patients' decision-making this should not be important because the important expectation for the patients is survival and HRQOL. It actually does not matter for the patients if future limitations are caused by a cardiac disease or other conditions expected as part of the general risk for disease. Finally, the inclusion of a variety of cardiac surgical procedures resulted in a heterogeneous study population, limiting the relevance of comparison with studies on CABG only. ${ }^{13,14}$ A questionnaire-based study will not identify all concerns experienced by the patients. Therefore, more information might be obtained by further studies using other designs such as qualitative interview techniques. 


\section{CONCLUSIONS}

This prospective cohort study showed that HRQOL generally was improved 10 years after cardiac surgery compared with before surgery. However, there was a decline on some scales from 12 months to 5 and 10 years, especially for older patients. These results corroborate international literature confirming long-term benefit on HRQOL and survival after cardiac surgery. This knowledge is crucial in discussing health care resources and patient-centered clinical decision-making. However, further knowledge is still needed concerning implementation in clinical practice in adherence with international guidelines.

\section{Conflict of Interest Statement}

Authors have nothing to disclose with regard to commercial support.

\section{References}

1. Shan L, Saxena A, McMahon R, Newcomb A. Coronary artery bypass graft surgery in the elderly: a review of postoperative quality of life. Circulation. 2013;128:2333-43.

2. Rumsfeld JS, Alexander KP, Goff DC Jr, Graham MM, Ho PM, Masoudi FA, et al. Cardiovascular health: the importance of measuring patient-reported health status: a scientific statement from the American Heart Association. Circulation. 2013; 127:2233-49.

3. Baig K, Harling L, Papanikitas J, Attaran S, Ashrafian H, Casula R, et al. Does coronary artery bypass grafting improve quality of life in elderly patients? Interact Cardiovasc Thorac Surg. 2013;17:542-53.

4. Tully PJ. Quality-of-life measures for cardiac surgery practice and research: a review and primer. J Extra Corpor Technol. 2013;45:8-15.

5. Kolh P, Windecker S, Alfonso F, Collett JP, Cremer J, Falk V, et al. 2014 ESC/EACTS guidelines on myocardial revascularization: the Task Force on Myocardial Revascularization of the European Society of Cardiology (ESC) and the European Association for Cardio-Thoracic Surgery (EACTS). Developed with the special contribution of the European Association of Percutaneous Cardiovascular Interventions (EAPCI). Eur J Cardiothorac Surg. 2014;46:517-92.

6. Deutsch MA, Krane M, Schneider L, Wottke M, Kornek M, Elhmidi Y, et al. Healthrelated quality of life and functional outcome in cardiac surgical patients aged 80 years and older: a prospective single center study. J Card Surg. 2014;29:14-21.

7. Noyez L, de Jager MJ, Markou AL. Quality of life after cardiac surgery: underresearched research. Interact Cardiovasc Thorac Surg. 2011;13:511-4.

8. Takousi MG, Schmeer S, Manaras I, Olympios CD, Makos G, Troop NA. Health-related quality of life after coronary revascularization: a systematic review with meta-analysis. Hellenic J Cardiol. August 23, 2016 [Epub ahead of print].

9. Jokinen JJ, Hippelainen MJ, Turpeinen AK, Pitkanen O, Hartikainen JE. Health-related quality of life after coronary artery bypass grafting: a review of randomized controlled trials. J Card Surg. 2010;25:309-17.

10. Blokzijl F, van der Horst IC, Keus E, Waterbolk TW, Mariani MA, Dieperink W. Quality of life in elder adults one-year after coronary bypass. J Vasc Nurs. 2016; 34:152-7.

11. Loponen P, Luther M, Wistbacka JO, Korpilahti K, Laurikka J, Sintonen H, et al. Quality of life during 18 months after coronary artery bypass grafting. Eur J Cardiothorac Surg. 2007;32:77-82.

12. Shan L, Saxena A, McMahon R, Wilson A, Newcomb A. A systematic review on the quality of life benefits after aortic valve replacement in the elderly. $J$ Thorac Cardiovasc Surg. 2013;145:1173-89.

13. Herlitz J, Brandrup-Wognsen G, Caidahl K, Hartford M, Haglid M, Karlson BW, et al. Determinants for an impaired quality of life 10 years after coronary artery bypass surgery. Int J Cardiol. 2005;98:447-52.
14. Hokkanen M, Jarvinen O, Huhtala H, Tarkka MR. A 12-year follow-up on the changes in health-related quality of life after coronary artery bypass graft surgery. Eur J Cardiothorac Surg. 2014;45:329-34.

15. Dunning J, Waller JR, Smith B, Pitts S, Kendall SW, Khan K. Coronary artery bypass grafting is associated with excellent long-term survival and quality of life: a prospective cohort study. Ann Thorac Surg. 2008;85:1988-93.

16. Gjeilo KH, Wahba A, Klepstad P, Lydersen S, Stenseth R. Survival and quality of life in an elderly cardiac surgery population: 5-year follow-up. Eur $J$ Cardiothorac Surg. 2013;44:e182-8.

17. Holland R, Rechel B, Stepien K, Harvey I, Brooksby I. Patients' self-assessed functional status in heart failure by New York Heart Association class: a prognostic predictor of hospitalizations, quality of life and death. J Card Fail. 2010;16:150-6.

18. Nashef SA, Roques F, Michel P, Gauducheau E, Lemeshow S, Salamon R. European system for cardiac operative risk evaluation (EuroSCORE). Eur $J$ Cardiothorac Surg. 1999;16:9-13.

19. Ware JE, Kosinski M, Gandek B. SF-36 Health Survey: Manual \& Interpretation Guide. 2nd ed. Lincoln, RI: Quality Metric Inc; 2000.

20. Loge JH, Kaasa S. Short form 36 (SF-36) health survey: normative data from the general Norwegian population. Scand J Soc Med. 1998;26:250-8.

21. Huber A, Oldridge N, Hofer S. International SF-36 reference values in patients with ischemic heart disease. Qual Life Res. 2016;25:2787-98.

22. Fagerland MW, Lydersen S, Laake P. Statistical Analysis of Contingency Tables. Boca Raton, Fla: Chapman \& Hall/CRC; 2017.

23. Greason KL, Lahr BD, Stulak JM, Cha YM, Rea RF, Schaff HV, et al. Long-term mortality effect of early pacemaker implantation after surgical aortic valve replacement. Ann Thorac Surg. 2017;104:1259-64.

24. Attia T, Koch CG, Houghtaling PL, Blackstone EH, Sabik EM, Sabik JF III. Does a similar procedure result in similar survival for women and men undergoing isolated coronary artery bypass grafting? J Thorac Cardiovasc Surg. 2017;153: 571-9.e579.

25. Alam M, Bandeali SJ, Kayani WT, Ahmad W, Shahzad SA, Jneid H, et al. Comparison by meta-analysis of mortality after isolated coronary artery bypass grafting in women versus men. Am J Cardiol. 2013;112:309-17.

26. Nicolini F, Vezzani A, Fortuna D, Contini GA, Pacini D, Gabbieri D, et al. Gender differences in outcomes following isolated coronary artery bypass grafting: long-term results. J Cardiothorac Surg. 2016;11:144.

27. Lassnigg A, Hiesmayr M, Frantal S, Brannath W, Mouhieddine M, Presterl E, et al. Long-term absolute and relative survival after aortic valve replacement: a prospective cohort study. Eur J Anaesthesiol. 2013;30:695-703.

28. Enger TB, Pleym H, Stenseth R, Greiff G, Wahba A, Videm V. Reduced long-term relative survival in females and younger adults undergoing cardiac surgery: a prospective cohort study. PLoS One. 2016;11:e0163754.

29. Jacobsen EL, Bye A, Aass N, Fossa SD, Grotmol KS, Kaasa S, et al. Norwegian reference values for the Short-Form Health Survey 36: development over time [erratum in 2018;27:1213-5]. Qual Life Res. 2018;27: 1201-12.

30. Peric V, Jovanovic-Markovic S, Peric D, Rasic D, Novakovic T, Dejanovic B, et al. Quality of life in patients of different age groups before and after coronary artery by-pass surgery. Ann Thorac Cardiovasc Surg. 2015;21:474-80.

31. Hammon JW. Preserved quality of life in octogenarians after cardiac surgery "pride cometh before the fall" Semin Thorac Cardiovasc Surg. 2016; 28:54-5.

32. Luckraz H, Nagarajan K, Chnaris A, Jayia PK, Muhammed I, Mahboob S, et al. Preserved quality of life in octogenarians at early, mid, and late follow-up intervals irrespective of cardiac procedure. Semin Thorac Cardiovasc Surg. 2016;28: 48-53.

33. O'Neill DE, Knudtson ML, Kieser TM, Graham MM. Considerations in cardiac revascularization for the elderly patient: age isn't everything. Can J Cardiol. 2016:32:1132-9.

34. Lytwyn J, Stammers AN, Kehler DS, Jung P, Alexander B, Hiebert BM, et al. The impact of frailty on functional survival in patients 1 year after cardiac surgery. $J$ Thorac Cardiovasc Surg. 2017;154:1990-9.

35. Altman DG, Bland JM. Missing data. BMJ. 2007;334:424.

Key Words: cardiac surgery, survival, quality of life, patient-reported outcomes, health surveys 
TABLE E1. Cox proportional hazard regression including all of the covariates simultaneously

\begin{tabular}{|c|c|c|c|c|}
\hline Covariate & $\mathbf{n} / \mathbf{N}^{*}$ & Hazard ratio estimate & CI & $P$ value \\
\hline \multicolumn{5}{|l|}{ Sex } \\
\hline Female (reference) & $47 / 121$ & 1 (Reference) & - & - \\
\hline Male & $125 / 413$ & 1.039 & 0.728 to 1.483 & .831 \\
\hline Age (per 10 y) & - & 2.167 & 1.772 to 2.649 & $<.001$ \\
\hline Type of surgery & & & & $.050 \dagger$ \\
\hline CABG (reference) & $103 / 365$ & 1 (Reference) & - & - \\
\hline HVS & $10 / 36$ & 0.868 & 0.449 to 1.679 & .675 \\
\hline CABG and HVS & $40 / 75$ & 1.598 & 1.089 to 2.344 & .017 \\
\hline Miscellaneous & $19 / 58$ & 1.465 & 0.896 to 2.395 & .128 \\
\hline
\end{tabular}

$C I$, Confidence interval; $C A B G$, coronary artery bypass grafting; $H V S$, heart valve surgery. ${ }^{*} \mathrm{n}$ of the $\mathrm{N}$ persons in this group died within 10 years. $\dagger$ Overall $P$ value for the 4 categories (3 degrees of freedom).

TABLE E2. Self-reported NYHA classification before and 10 years after cardiac surgery among all patients

\begin{tabular}{|c|c|c|c|c|c|}
\hline & \multicolumn{4}{|c|}{ NYHA classification after 10 years } & \multirow[b]{2}{*}{ Total, $(\%)$} \\
\hline & $\mathbf{I}$ & II & III & IV & \\
\hline \multicolumn{6}{|c|}{ Preoperative NYHA classification } \\
\hline I & 37 & 12 & 2 & 0 & $51(20.2)$ \\
\hline II & 58 & 29 & 8 & 0 & $95(37.5)$ \\
\hline III & 42 & 32 & 11 & 4 & $89(35.2)$ \\
\hline IV & 8 & 6 & 3 & 1 & $18(7.1)$ \\
\hline Total, $(\%)$ & $145(57.3)$ & $79(31.2)$ & $24(9.5)$ & $5(2.0)$ & $253(100)$ \\
\hline
\end{tabular}

NYHA, New York Heart Association.

TABLE E3. Self-reported NYHA classification before and 10 years after cardiac surgery among patients younger than 75 years at surgery

\begin{tabular}{|c|c|c|c|c|c|}
\hline & \multicolumn{4}{|c|}{ NYHA after 10 years } & \multirow[b]{2}{*}{ Total, $(\%)$} \\
\hline & $\mathbf{I}$ & II & III & IV & \\
\hline \multicolumn{6}{|c|}{ Preoperative NYHA classification } \\
\hline I & 31 & 11 & 1 & 0 & 43 (19.5) \\
\hline II & 55 & 28 & 5 & 0 & $88(40.4)$ \\
\hline III & 37 & 27 & 9 & 3 & $76(34.5)$ \\
\hline IV & 8 & 4 & 1 & 0 & $13(5.9)$ \\
\hline Total, $(\%)$ & $131(59.5)$ & $70(31.8)$ & $16(7.3)$ & $3(1.4)$ & $220(100)$ \\
\hline
\end{tabular}

NYHA, New York Heart Association.

TABLE E4. Self-reported NYHA classification before and 10 years after cardiac surgery among patients 75 years of age or older at surgery

\begin{tabular}{|c|c|c|c|c|c|}
\hline & \multicolumn{4}{|c|}{ NYHA after 10 years } & \multirow[b]{2}{*}{ Total, (\%) } \\
\hline & $\mathbf{I}$ & II & III & IV & \\
\hline \multicolumn{6}{|c|}{ Preoperative NYHA classification } \\
\hline I & 6 & 1 & 1 & 0 & $8(24.2)$ \\
\hline II & 3 & 1 & 3 & 0 & $7(21.2)$ \\
\hline III & 5 & 5 & 2 & 1 & $13(39.4)$ \\
\hline IV & 0 & 2 & 2 & 1 & $5(15.2)$ \\
\hline Total, $(\%)$ & $14(42.4)$ & $9(27.3)$ & $8(24.2)$ & $2(6.1)$ & $33(100)$ \\
\hline
\end{tabular}

NYHA-class, New York Heart Association classification. 
TABLE E5. Estimated mean SF-36 scores at baseline, 6, and 12 months, and 5 and 10 years after cardiac surgery

\begin{tabular}{|c|c|c|c|c|c|c|}
\hline SF-36 dimension & $\begin{array}{c}\text { Baseline } \\
(\mathrm{n}=\mathbf{4 9 3 - 5 2 8})^{*}\end{array}$ & $\begin{array}{c}6 \mathrm{mo} \\
(\mathrm{n}=419-456)^{*}\end{array}$ & $\begin{array}{c}12 \mathrm{mo} \\
(\mathrm{n}=\mathbf{4 2 6}-458)^{*}\end{array}$ & $\begin{array}{c}5 y \\
(n=335-361)^{*}\end{array}$ & $\begin{array}{c}10 y \\
(n=252-267)^{*}\end{array}$ & $\begin{array}{c}P \text { time } \times \\
\text { group }\end{array}$ \\
\hline \multicolumn{7}{|l|}{ GH } \\
\hline$<75 y$ & $64.9(1.1)$ & 70.5 (1.1) & 70.7 (1.1) & $67.1(1.2)$ & $65.4(1.3)$ & .729 \\
\hline$\geq 75 \mathrm{y}$ & $63.9(2.1)$ & $69.0(2.2)$ & $67.5(2.2)$ & $63.7(2.5)$ & $60.8(3.1)$ & \\
\hline \multicolumn{7}{|l|}{ PF } \\
\hline$<75 \mathrm{y}$ & $59.2(1.2)$ & 80.5 (1.3) & $80.0(1.3)$ & $76.2(1.3)$ & 73.0 (1.4) & $<.0001$ \\
\hline$\geq 75 y$ & $48.9(2.2)$ & $65.7(2.4)$ & $65.4(2.3)$ & $56.5(2.7)$ & $43.3(3.5)$ & \\
\hline \multicolumn{7}{|l|}{ SF } \\
\hline$<75 y$ & 72.4 (1.2) & $83.4(1.2)$ & $86.0(1.2)$ & $83.8(1.3)$ & 83.9 (1.4) & .014 \\
\hline$\geq 75 y$ & $71.5(2.2)$ & $81.1(2.3)$ & $81.7(2.3)$ & 76.7 (2.6) & $71.2(3.4)$ & \\
\hline \multicolumn{7}{|l|}{ RP } \\
\hline$<75 \mathrm{y}$ & $23.5(2.1)$ & $60.3(2.2)$ & $60.3(2.2)$ & $57.8(2.3)$ & $54.5(2.5)$ & .001 \\
\hline$\geq 75 y$ & $13.5(3.8)$ & $35.8(4.2)$ & $33.1(4.1)$ & $26.6(4.8)$ & $29.9(6.6)$ & \\
\hline \multicolumn{7}{|l|}{ RE } \\
\hline$<75 y$ & $58.7(2.0)$ & $74.2(2.1)$ & $74.8(2.1)$ & $77.1(2.3)$ & $75.5(2.5)$ & .145 \\
\hline$\geq 75 \mathrm{y}$ & $51.4(3.7)$ & $57.7(4.1)$ & $60.7(4.0)$ & $56.1(4.7)$ & 60.7 (6.6) & \\
\hline \multicolumn{7}{|l|}{ MH } \\
\hline$<75 \mathrm{y}$ & $75.5(0.8)$ & 80.7 (0.9) & $80.7(0.9)$ & $81.6(0.9)$ & $80.8(1.0)$ & .173 \\
\hline$\geq 75 y$ & 76.8 (1.6) & 80.7 (1.6) & $80.6(1.6)$ & 79.0 (1.9) & $76.7(2.4)$ & \\
\hline \multicolumn{7}{|l|}{ VT } \\
\hline$<75 y$ & $48.8(1.1)$ & $61.3(1.2)$ & $60.0(1.2)$ & $58.5(1.2)$ & $59.4(1.3)$ & .019 \\
\hline$\geq 75 \mathrm{y}$ & $50.2(2.1)$ & $58.0(2.2)$ & $57.8(2.2)$ & $53.0(2.5)$ & $51.1(3.1)$ & \\
\hline \multicolumn{7}{|l|}{$\mathrm{BP}$} \\
\hline$<75 \mathrm{y}$ & $55.7(1.3)$ & $73.8(1.4)$ & 76.5 (1.4) & $72.6(1.5)$ & $70.0(1.6)$ & .675 \\
\hline$\geq 75 y$ & $56.2(2.5)$ & $74.0(2.6)$ & $78.0(2.6)$ & $68.7(3.1)$ & $69.5(4.0)$ & \\
\hline
\end{tabular}

Linear mixed model with time and age groups at surgery and their interaction as covariates, adjusted for sex. Linear mixed model fitted for age group, adjusted for sex. Data are estimated sample mean and SE except where otherwise noted. Higher scores reflect better health. SF-36, Short-Form Health Survey; $G H$, general health; $P F$, physical functioning; $S F$, social functioning; $R P$, role physical; $R E$, role emotional; $M H$, mental health; $V T$, vitality; $B P$, bodily pain. *The number of cases varies because of differences in the number missing at each dimension of the SF-36. 